\title{
Baked Chips Developed from Bitter Gourd, Moong Dal Flour and Gymnema Sylvestre (Asclepiadaceae) Reduce Blood Glucose Levels in Diabetes Mellitus
}

\author{
Luxita Sharma* \\ Assistant Professor - II \& Head Dietetics and Applied Nutrition, India \\ *Corresponding author: Luxita Sharma, Assistant Professor - II \& Head Dietetics and Applied Nutrition, India
}

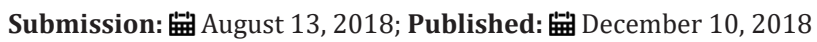

\begin{abstract}
Functional foods are a wide variety of food products, of which some are even classified as nutrients, influencing a variety of body functions that are important to either a condition of prosperity or well-being or diminishment in a danger of certain interminable illness. Nutrition has advanced from the aversion of dietary deficiency and the foundation of nutrition standards, dietary rules and food guides to the advancement of a state of well-being and health and the reduction of the danger of ailments.

The present study is focused on developing a food product helpful in managing Diabetes Mellitus with its acceptability studies to the industry as well as the society. The baked chips were made from the variations in bitter gourd powder and rest ingredients as in same weight. Five variations were prepared in different ratios. Then a panel of trained experts decide the best sample in terms of taste, color, texture, stickiness and overall acceptability. Sample D was rated best and then it was administered to fifty subjects suffering from Diabetes Mellitus. The incorporation of Eight chips in the diet of Diabetic patients resulted in significant decrease in blood glucose levels. The food products are better way to heal people with positive mind as people relish the food product otherwise nobody will be eating bitter gourd as its taste is very bitter.
\end{abstract}

\section{Introduction}

New product development is a sequence of steps that has the conception, design, development and marketing of a newly created or a freshly branded good. The product can be substantial or immaterial. Across the globe, populations are aging, life expectancy continues to decrease and furthermore illness for example; obesity, cancers and cardiovascular diseases have now become the primary cause of death. Diabetes is defined as a disease that has the blood glucose levels are too high. The foods after digestion gets converted to Glucose and then are absorbed in the liver to metabolize. The hormones Insulin secreted from pancreas helps to transport the glucose into the cells and provides energy [1].

The two types of Diabetes Mellitus are type 1 diabetes and type II. In the type I Diabetes Mellitus the body have less cells producing insulin while in type 2 diabetes the insulin is not produced at all. The glucose transportation is very difficult without enough insulin and this is the reason for increased glucose in the blood. There is a condition called pre-diabetes and this implies that blood sugar is at higher levels, not be called as Diabetes Mellitus. Pre-Diabetes is a condition that increases chances of an individual to suffer from Diabetes Mellitus. Too much glucose can cause serious issues in the body which includes damage to eyes, kidneys, brain, neuromuscular disorders, GI disorders and skin problems. The heart is also affected deeply with the increased blood glucose levels. Gestational type of Diabetes affects the pregnant women [2]. The etiology of Diabetes is dependent on the genetics, family history, race, health environmental factors, impaired glucose tolerance, obesity, age and sedentary lifestyle. And we are particularly concerned about the increasing burden of diabetes on the health and wellbeing of Indians. The statistics paint the picture. Too many Indians have the disease. We want to see that Figure $1 \& 2$ reduced. Undiagnosed diabetes is a significant issue [3].

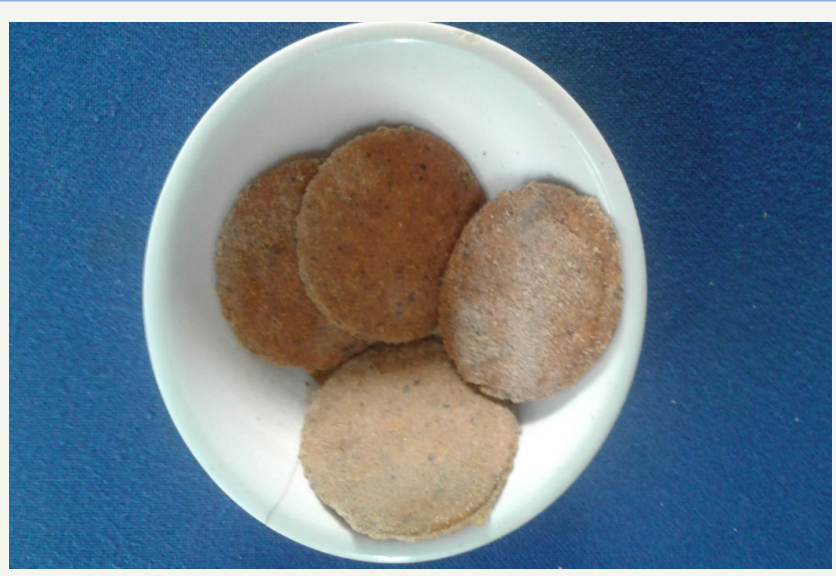

Figure 1: Sample A contains 3G of bitter gourd. 


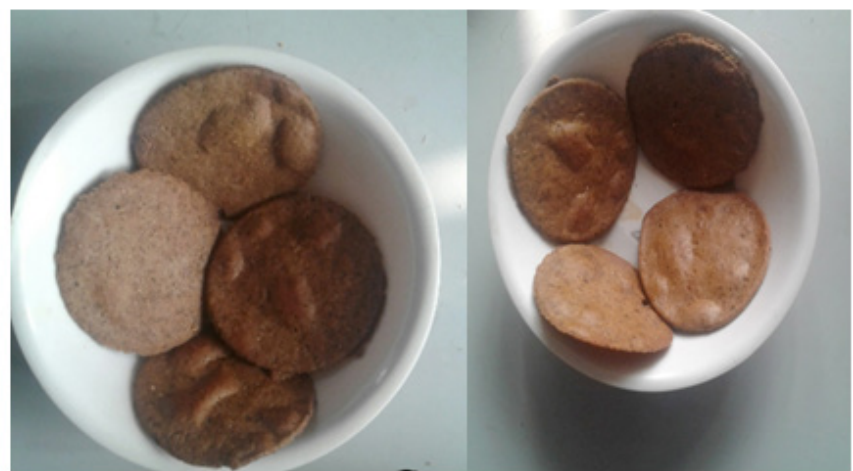

Sample B: Contains 96 of Bitter Gourd

Sample C: Contains 56 of Bitter Gourd

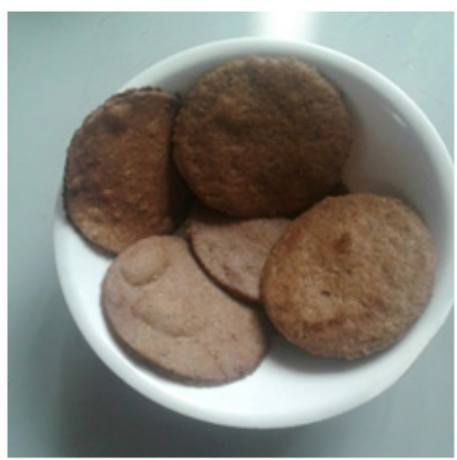

Sample D: Contains $11 \mathrm{G}$ of Bitter Gourd

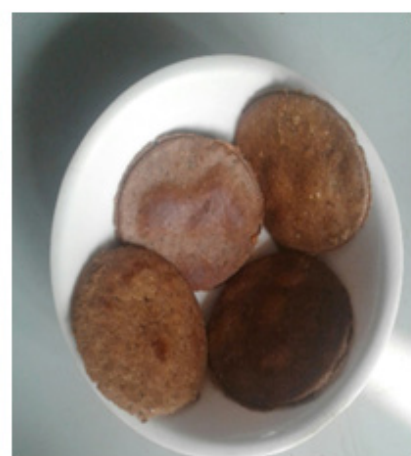

Sample E: Contains $7 G$ of Bitter Gourd

Figure 2:

Diabetes can be controlled and cured mainly by the food that we eat. Nowadays scientists are researching for the anti-diabetic properties present in different food items and production of several food items combined with natural antidiabetic herbs. These days the demands are high for these products. So, keeping in mind the baked chips contain bitter gourd, moong dal flour and Gymnema sylvestre were prepared. The main compound present in Bitter gourd is an insulin-like compound called Polypeptide-p or p-insulin which has the properties to reduce blood glucose levels.

\section{Review of Literature}

Scientific studies have also established that many chronic diseases such as Diabetes Mellitus, cardiovascular disease, hypertension and obesity, among others, are directly related to the type of food being consumed. This change in the tastes, preferences and the demands of modern consumers have created a new area of development and challenges in food and nutritional science. Within this context, the aim of this paper is to develop a product using chia seeds and exploit its various benefits and potentials. A study done proved that a four-week clinical trial on diabetic subjects resulted in reduction of blood glucose and the quantity prescribed was $2,000 \mathrm{mg}$ of bitter gourd when taken on regular basis. Yellow moong dal refers to moong beans that have been skinned and split, so that they're flat, yellow, and quick-cooking. They're relatively easy to digest. They can be made into moong bean paste by de-hulling, cooking, and pulverizing the beans to the consistency of a dry paste.
Gymnema sylvestre is a natural herb which have sugar level lowering properties. Many Scientists have completed the researches on the antidiabetic properties of the herb. The study included the Antidiabetic effect of a leaf extract from Gymnema sylvestre on NIDDM (non-insulin-dependent diabetes mellitus) patients (K. Bhaskaran,1990). An extract of Gymnema sylvestre called GS4, has role in controlling hyperglycemia was investigated. It showed that the patients showed a significant reduction in blood glucose, glycosylated hemoglobin and glycosylated plasma proteins. Five of the 22 diabetic patients were able to discontinue their conventional drug and maintain their blood glucose homeostasis with GS4 alone. These data proposed that the beta cells may be regenerated/ repaired in Type II diabetic patients on GS4 supplementation.

\section{Aims and Objectives}

a) To develop a nutritionally adequate food product/ supplement from naturally available food groups containing essential food nutrients: energy, carbohydrates, proteins, fats, vitamins.

b) To study the organoleptic properties of the food product/ supplement by developing variations.

c) To find out the nutritional composition in terms of calories, proteins, fats and other specific nutrients.

d) To study the effect of administration of developed food product on the patients suffering from Diabetes mellitus. 


\section{Materials and Methods}

\section{Development of food product (Bitter gourd Baked Chips)}

Expending the above standardized recipe, bitter gourd chips were advanced by combining the bitter gourd powder + moong dal floor +Gymnema sylvestre in the ratio of 45:55, 60:40, 70:30, 15:85 and $80: 20$ by the subsequent processes.

\section{Steps in developing food product}

Development of bitter gourd chips progressed with the mixing of ingredients and preparing dough. At first take a bowl and pour moong dal flour in it and gradually add bitter gourd powder which is being made from drying and grinding it, add 3gms of Gymnema sylvestre, add 4-5 seeds of fenugreek in it, add 1 teaspoon of dry mango powder, add salt to taste, a pinch of baking powder and black pepper powder. After that gradually pour Luke warm water on it and then prepare dough. Left the dough for 10 minutes and then knead it with rolling pin. And then prepare a desire shaped chips from it; and finally baked them for 10 minutes at 120 degree. Baked bitter gourd chips are ready to serve with some delicious sauce.

Repeat all these steps for rest of the different ratios that have to be made. Put the prepared sample in 5 different bowls and name them as A, B, C, D, E. Sensory Evaluation of baked bitter gourd chips was made on the basis of sensory categories, including color, taste, texture, crispiness, firmness and acceptability by 20 panelists. Each characteristic was assessed on an intensity rating scale and was separately reported. Seven-point scales were described for the sensory evaluation (hedonic test), and each class was rated from 1 (Poor) to 10 (like extremely). (poor, extremely dislike, dislike very much, dislike moderately, dislike slightly, neither like nor dislike, like slightly, like moderately, strongly like and like extremely) in order to assess the statistical significance of the test, so that higher scores indicate higher preferences.

The preferences of the panelists for the chips incorporated with different percentages of flour ratio are presented. After conducting the sensory evaluation statistical analysis was done in the basis of mean and standard deviation of all attributes. The chips were then sealed packed and a pilot study on twenty patients was done.

Selection of the subjects: Fifty subjects were selected randomly from the village of Panchagon, Manesar, India.
Inclusion criteria: All subjects were suffering from Diabetes Mellitus with Fasting sugar levels above $120 \mathrm{mg} / \mathrm{dl}$. The subjects were not following any dietary restrictions. They were free from any serious ailments. The prior consent was taken before the interventions.

Exclusion criteria: The subjects who failed to give consent. The pre-diabetics were excluded

\section{Tools used}

After the subject's distribution was done then to collect the data, researcher made questionnaire which was based on the demographic details, medical history and 24-hour recall was used. All the experimental group and control groups filled the questionnaires before the interventions were started. The questionnaire which was developed by taking references of similar studies. Then the validity of the questionnaire was investigated by an expert panel of seven experts which included five nutritionists and two doctors. The questionnaire was given to experts and they were asked to provide their opinions of related, weakly related, related and strongly related. Then according to the recommendations of the panel of the expert's questionnaire was modified and finalized. The next step was to calculate the reliability of the questionnaire, a pilot study on 20 subjects was carried out. The Cronbach's $\alpha$ coefficient $(0.88)$ were all at the favorable level. The results of pre-test groups showed that the subjects were not eating healthy food Then an educational intervention programmed was designed for the experimental groups. The diabetic subjects followed the interventions for six weeks $[4,5]$.

\section{Results and Discussion}

The main reason behind making this recipe was its nutritive value and medicinal value mainly for diabetes and several other diseases. It is basically made for diabetic people and obese people, but anyone can consume it for better health and to avoid prediabetic condition Table 1. After the sensory evaluation, the product was statistically analyzed using mean and standard deviation. Table 2 below shows the results of sensory evaluation in the form of mean and standard deviation of the product. Table 2 shown, the sample D containing $5 \mathrm{gm}$ of bitter gourd is rated the best in every aspects such as taste, color, texture, stickiness, acceptability followed by the sample containing $9 \mathrm{gms}$ of bitter gourd then followed by $3 \mathrm{gms}$ futher followed by $7 \mathrm{gms}$ and the least rating containing $11 \mathrm{gms}$ of biter gourd.

Table 1: Nutritional composition of the food product ingredients.

\begin{tabular}{|c|c|c|c|c|c|c|c|}
\hline $\begin{array}{c}\text { Nutrient Value } \\
\text { Ingredients }\end{array}$ & $\begin{array}{c}\text { Moisture } \\
\text { (g) }\end{array}$ & $\begin{array}{c}\text { Protein } \\
\mathbf{( g )}\end{array}$ & $\begin{array}{c}\text { Fats } \\
\mathbf{( g )}\end{array}$ & $\begin{array}{c}\text { Carbohydrates } \\
\text { (g) }\end{array}$ & $\begin{array}{c}\text { Energy } \\
\text { (Kcal) }\end{array}$ & $\begin{array}{c}\text { Iron } \\
\text { (mg) }\end{array}$ & $\begin{array}{c}\text { Phosphorus } \\
\text { (mg) }\end{array}$ \\
\hline Bitter gourd & 92.4 & 1.6 & 0.2 & 4.2 & 25 & 0.61 & 70 \\
\hline Moong dal flour & 10.1 & 24.5 & 1.2 & 59.9 & 348 & 3.9 & 405 \\
\hline Gymnema sylvestre & - & - & - & - & - & - & - \\
\hline Fenugreek seeds & 13.7 & 26.2 & 5.8 & 44.1 & 333 & 6.5 & 370 \\
\hline Total & 116.2 & 52.3 & 7.2 & 108.2 & 706 & 11.01 & 845 \\
\hline
\end{tabular}

*Values according to ICMR 1989 
Table 2: Acceptability scores of the food product developed with dried bitter gourd variations.

\begin{tabular}{|c|c|c|c|c|c|}
\hline Ratios- & $A[80: 20] 11 \mathrm{gm}$ & $\mathrm{B}[70: 30] 9 \mathrm{gm}$ & $\mathrm{C}[60: 40] 7 \mathrm{gm}$ & $\mathrm{D}[45: 55] 5 \mathrm{gm}$ & $\mathrm{E}[15: 85] 3 \mathrm{gm}$ \\
\hline Taste & $5.6 \pm 0.50^{\wedge[4]}$ & $7.95 \pm 0.75^{\wedge[2]}$ & $7.75 \pm 0.71^{\wedge[3]}$ & {$[1] 8.75 \pm 0.44^{\wedge[1]}$} & $7.7 \pm 0.73^{\wedge[3]}$ \\
\hline Color & $6.55 \pm 0.60^{\wedge[5]}$ & $8.95 \pm 0.60^{\wedge[2]}$ & $8.85 \pm 0.67^{\wedge[3]}$ & $9.06 \pm 0.68^{\wedge[1]}$ & $8.4 \pm 0.59^{\wedge[4]}$ \\
\hline Texture & $5.4 \pm 0.68^{\wedge[5]}$ & $8.45 \pm 0.68^{\wedge[4]}$ & $8.65 \pm 0.48^{\wedge[3]}$ & $9.05 \pm 0.60^{\wedge[1]}$ & $9 \pm 0.64^{\wedge[2]}$ \\
\hline Firmness & $5.65 \pm 0.48^{\wedge[5]}$ & $8.65 \pm 0.38^{\wedge[2]}$ & $8.5 \pm 0.51^{\wedge[3]}$ & $9.05 \pm 0.60^{\wedge[1]}$ & $8.35 \pm 1.03^{\wedge[4]}$ \\
\hline Stickiness & $5.8 \pm 0.52^{\wedge[2]}$ & $5.6 \pm 0.50^{\wedge[3]}$ & $5.55 \pm 0.51^{\wedge[4]}$ & $5.55 \pm 0.60^{\wedge[4]}$ & $5.9 \pm 0.64^{\wedge[1]}$ \\
\hline Acceptability & $5.7 \pm 0.47^{\wedge[5]}$ & $8.4 \pm 0.50^{\wedge[2]}$ & $5.95 \pm 0.68^{\wedge[4]}$ & $9.1 \pm 0.44^{\wedge[1]}$ & $8.15 \pm 0.67^{\wedge[3]}$ \\
\hline After taste & $9.8 \pm 0.41^{\wedge[1]}$ & $7.7 \pm 0.80^{\wedge[3]}$ & $8.7 \pm 0.47^{\wedge[4]}$ & $5.35 \pm 0.67^{\wedge}\{2\}$ & $3.05 \pm 0.75^{\wedge[5]}$ \\
\hline
\end{tabular}

NS-Non-Significant Value* Significant value at $(\mathrm{P}<0.05){ }^{* *}$ Significant value at $(\mathrm{P}<0.01)$

The best sample was selected after the sensory evaluation. Chips made from $5 \mathrm{gms}$ bitter gourd powder and 3gms of the Gymnema sylvestre were selected to administer the patients two times daily. Around Eight chips were served to the patients daily with food. The fasting blood levels were measured daily. The results of pretest and post test are as follows, Table 3 shows that the experimental group had mean high fasting glucose levels before the study. The subjects were fed eight chips per day with the meals and after six weeks the fasting blood glucose levels were again tested. The mean blood glucose levels came down to $121.5+12.2$. The Body mass Index was also calculated, no doubt the study did not aim to reduce weight but when the weight was taken, and BMI was calculated, the results were amazing. The mean BMI came down from $29.25+2.46$ to $27.2+2.48$

Table 3: Effect of administration of the food product on the diabetic patients

\begin{tabular}{|c|c|c|c|c|c|}
\hline Parameters & Blood Glucose Levels & T value & Body Mass Index & T Value & P Value \\
\hline Experimental Group & & \multirow[b]{3}{*}{$1.29^{* *}$} & & \multirow[b]{3}{*}{$2.55^{* *}$} & \multirow[b]{3}{*}{0} \\
\hline (Pr -test) & $144.4 \pm 15$ & & $29.25 \pm 2.46$ & & \\
\hline Experimental Group (Posttest) & $121.5 \pm 12.2$ & & $27.2 \pm 2.48$ & & \\
\hline Control Group (Pretest) & $149.05 \pm 12.9$ & \multirow[b]{2}{*}{$.39 \mathrm{NS}$} & $30.01 \pm 2.05$ & \multirow[b]{2}{*}{$.076 \mathrm{NS}$} & \multirow[b]{2}{*}{0.9} \\
\hline Control Group (Posttest) & $150 \pm 13.8$ & & $29.25 \pm 2.46$ & & \\
\hline
\end{tabular}

\section{Conclusion}

Subsequently the evaluation of chemical composition of baked bitter gourd chips containing 5grams of bitter gourd and 20grams of moong dal flour has resulted that the product is rich in protein, iron, carbohydrate, phosphorus and meet the daily requirement of carbs, protein and fat and energy. since it is better food product for diabetic, pre- diabetic patient and obesity and for other diseases. it has been proved after the administration to the diabetic patients as well. the fasting blood glucose levels decreased significantly after the food intake of baked chips made up of bitter gourd and an herb Gymnema sylvestre. Therefore, the bitter gourd chips can be helpful in decreasing blood sugar levels, but more studies are required to reach a concrete conclusion.

\section{References}

1. Wild S, Roglic G, Green A, Sicree R, King H (2004) Global prevalence of diabetes-estimates for the year 2000 and projections for 2030. Diabetes Care 27(3): 1047-1053.

2. Kumar A, Goel MK, Jain RB, Khanna P, Chaudhary V (2013) India towards diabetes control: Key issues. Australas Med J 6(10): 524-531.

3. Whiting Dr, Guariguata L, Weil C, Shawj (2011) IDF diabetes atlas: Global estimates of the prevalence of diabetes for 2011 and 2030. Diabetes Res ClinPract 94(3): 311-321.

4. Joshi SR, Parikh RM (2007) India-diabetes capital of the world: Now heading towards hypertension. J Assoc Physicians India 55: 323-324.

5. Mohan V, Deepa M, Farooq S, Datta M, Deepa R (2007) Prevalence, awareness and control of hypertension in Chennai-the Chennai urban rural epidemiology study (CURES-52). J Assoc Physicians Ind 55: 326332.
Creative Commons Attribution 4.0 International License

For possible submissions Click Here

\section{Submit Article}

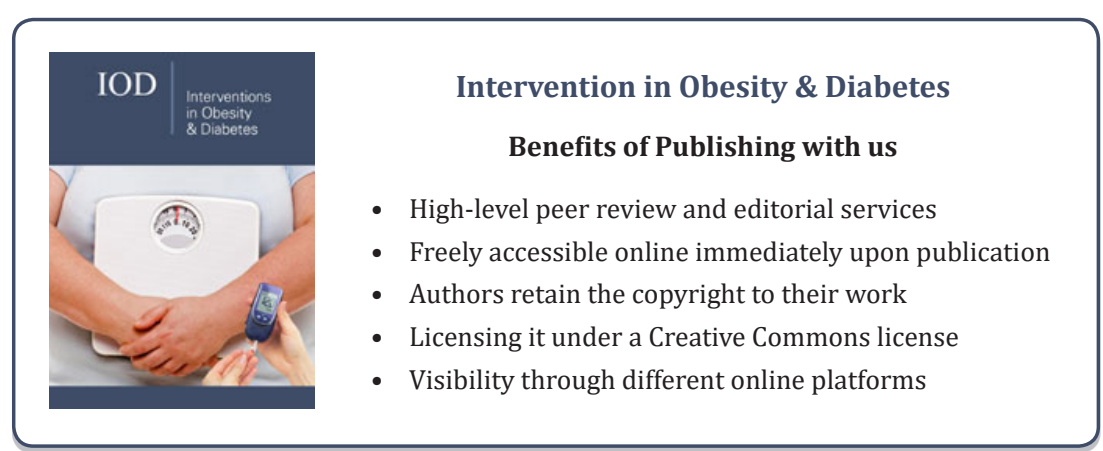

